\title{
Students Perceptions Towards Industrial Attachment in Kumasi: An Ordinal logistic Approach
}

\author{
Maxwell B. Asare' ${ }^{1}$, Robert K. Antwiadjei-Manu' ${ }^{2}$ Kofi A. Ababio ${ }^{3}$ \\ ${ }^{1}$ Department of Applied Statistics, University for Development Studies, Tamale, Ghana \\ ${ }^{2}$ Administrations but Registry, Kumasi Polytechnic, Kumasi, Ghana \\ ${ }^{3}$ Department of Mathematics and Statistics, Kumasi Polytechnic, Kumasi, Ghana
}

Email address:

abmaxwel19@gmail.com (M. B. Asare)

\section{To cite this article:}

Maxwell B. Asare, Robert K. Antwiadjei-Manu, Kofi A. Ababio. Students Perceptions Towards Industrial Attachment in Kumasi: An Ordinal logistic Approach. Science Journal of Applied Mathematics and Statistics. Vol. 3, No. 6, 2015, pp. 275-280.

doi: 10.11648/j.sjams.20150306.11

\begin{abstract}
The association of four ordered categories of student's perceptions towards challenges in industrial attachment program with socio-demographic characteristics is researched in this study. The ordered nature of responses motivated the use of ordinal logistic model. With the aid of questionnaire, data were gathered from students who were serving in various institutions within the Kumasi metropolis of Ghana. We developed a latent variable model from the ordinal logistic model for thresholds of the categories of student's perceptions towards industrial attachment. Gender and marital status showed negative relationship on students' perception about industrial attachment. However, for place of attachment, supervisor and office space positive associations were found. We evaluated the validity of our model using the assumption of parallel lines.
\end{abstract}

Keywords: Kumasi Metropolis, Industrial Attachment, Socio-demographic, Model, Challenges, Parallel Line, Undergraduate, Relationship

\section{Background of the Study}

Employment is much more than just getting your first job - it is about having a positive self-image and presenting yourself successfully, both as a new graduate and throughout your life. Your skills, knowledge and personal attributes and the ability to convey them effectively, all contribute to your employability as is your personal circumstances and labor market conditions.

As a matter of urgency, most higher learning institutions in this country offer attachment for their undergraduate students to provide a smooth transition from the academic world to the working environment. Attachments have taken on an increasingly important role in higher education over the past decade (Tackett et al., 2001, cited from Muhammad et.al, 2009). The main purpose was to enable undergraduate students to acquire working experience and practical knowledge into their formal education in the higher education; in order to prepare them very well for the job market. Industrial attachment enables undergraduate students to be able to translate their classroom work to the workplace. Industrial attachment establishes company contacts that may lead to future employments for students.

The objective of this study is to examine the association between student's perception about industrial attachment and their socio-demographic characteristics. Data used in this study comes from students who were serving on attachment grounds in several institutions in the Kumasi metropolis of Ghana. The following question motivated the research: What is student's perception on industrial attachment?

This study would assist tertiary institutions particularly those in the metropolis in making necessary amendments in the management of their existing Students Industrial Attachment Programme (SIAP). To investigate the challenges students faced during their attachment.

During attachment period, students in industries or institutions would have an opportunity to interact using senses. For example, students will see what is done, hear what is said, feel the work relationships, hear what is said about them and their attachment programme which would help develop perceptions or attitudes towards the whole programme.

However, what an individual interprets or perceives may be substantially different from reality. Perceptions are 
sometimes inaccurate, for example, in illusions. Psychologists agree on the following perceptive psychological principles (Petter, 2009).

A positive perception occurs when practical knowledge gained by students during their industrial placement can be applied to classroom theory (Kamunzyu and NdungeLuu, 2006).

A negative perception develops when students start to realize that many operational issues and practices, which have been learned in the classroom, are different from what they have experienced in practice (Kamunzyu and Ndunge Luu, 2006).

On the other hand, institutions of learning from which students come, also benefit from the SIAP programs. It provides them with an opportunity to improve their curricular. Gumbe, Scotia and Mupambireyi (2012) point out that this can be inferred from the studies that were carried out by Samuel (2005) in which he reports that the Industrial Training Fund in Nigeria established the existence of a wide gap between theory and practice of engineering and technology and other practically oriented courses. Therefore one can conclude that findings of this nature spur learning institutions to improving their curricula to meet industry needs. This is confirmed by Ogunlade's findings (2009) at Riyadh College of Technology which asserted that students had their academic skills improved after attachment as they had relevant academic knowledge.

Dickinson (2010) states that trainees need to be bold, confident and ready to move into action during the learning process.

Carlson (2002) as cited in Gumbe, Scotia and Mupambireyi (2012) identified the following as challenges that are associated with attachment: competition for attachment places from other institutions; rough and tough work environment for students; male dominated working environment for female trainees and high expectations by firms accepting attaches' Carlson's (ibid) assertions on industrial attachment are corroborated by Afonja et al (2005), however Olugbenga's (2009) concurs with the former authors but adds that students on industrial attachment also face financial challenges.

Despite the challenges faced one can conclude from the reviewed literature that attachment programs play an important role to both industry and attachés'.

\section{Methodology}

Statistical Methodology

This section presents the theory of statistical methods used to analyze the Students Industrial Attachment Programme (SIAP) data. The ordinal logistic regression is the major tool utilized in this paper. Specifically, the proportional odds (PO) version of the ordinal logistic model is used. Assuming $\mathrm{Y}$ is a categorical response variable with $\mathrm{c}$ ordered categories. The proportional odds (PO) model sometimes called the cumulative logit model models the $\log$ odds of the first $\mathrm{c}-1$ cumulative probabilities as

$$
\begin{aligned}
\operatorname{Logit}[\operatorname{pr}(\mathrm{Y} \leq i)]= & \ln \left[\frac{\operatorname{pr}(\mathrm{Y} \leq i)}{1-\operatorname{pr}(\mathrm{Y} \leq i)}\right], \quad \mathrm{i}=1 \ldots \mathrm{c}-1 \\
& =\ln \left[\frac{\pi_{i}}{1-\pi_{i}}\right]
\end{aligned}
$$

The quantity to the left of the equal sign is called a logit. It is the log of the odds that an event occurs. The odd that an event occurs is the ratio of the number of people who experience the event to the number of people who do not. The PO model has been described by McCullagh (1980) as the most popular ordinal logistic model. The relationship between the cumulative logit of $\mathrm{Y}$ is

$$
\ln \left[\frac{\pi_{i}}{1-\pi_{i}}\right]=\ln \left[\frac{\pi_{i}}{\pi_{i+1+\cdots+\pi_{i}}}\right], \mathrm{i}=1 \ldots \mathrm{c}-1
$$

Consider a collection of $p$ explanatory variables denoted by the covariate vector $X^{\prime}=\left(X_{1}, X_{2}, \ldots, X_{p}\right)$, to estimate the $\ln$ (odds) or logit of being at or below the jth category, the PO model can be rewritten as

$$
\begin{aligned}
\operatorname{Logit}[\pi(\mathrm{Y} & \left.\leq \mathrm{i} / X_{1}, X_{2}, \ldots X_{p}\right]=\ln \left[\frac{\pi\left(\mathrm{Y} \leq \mathrm{i} / X_{1}, X_{2}, \ldots X_{p}\right.}{\pi\left(\mathrm{Y}>\mathrm{i} / X_{1}, X_{2}, \ldots X_{p}\right.}\right] \\
& =\propto_{i}+\left(-\beta_{1} X_{1}-\beta_{2} X_{2}-\cdots-\beta_{p} X_{p}\right)
\end{aligned}
$$

Wherei $=1=\mathrm{c}-1$, therefore leading to $\mathrm{c}-1$ logits.

Each logit has its own i term called the threshold value and their values do not depend on the independent variables. The model assumes linear relationship for each logit. Moreover, it assumes that the logit are parallel lines. The assumption of parallelism is evaluated through the "test of parallel lines" by comparing the PO model which has one set of coefficients for all thresholds to a model with a separate set of coefficients for each threshold. Moreover, the PO model can be expressed as a latent variable model (Agresti, 2002).

Assuming a latent variable, $Y^{*}$ exists, $Y^{*}=x \beta+\varepsilon$, can be defined where $x$ is a row vector $(1 \times k)$ containing no constant, $\beta$ is a column vector $(\mathrm{kX} 1)$ of structural coefficients, and $\varepsilon$ is random error with standard normal distribution. Let $Y^{*}$ be divided by some cut points (thresholds): $\propto_{1}, \propto_{2}, \propto_{3}, \ldots . \propto_{c-1}$ where $\propto_{1}<\propto_{2}<\propto_{3}<\ldots .<$ $\propto_{c-1}$. The latent variable model for $c$ categories of the response variable $Y$ can be expressed as

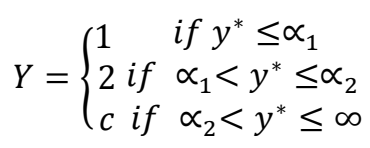

\section{Results and Discussions}

This study used tertiary education students who were schooling in the various regions of Ghana and were found doing industrial attachment during $20^{\text {th }}$ May to $20^{\text {th }}$ September 2014 (long vacation period) in Kumasi. Entirely, 350 students were surveyed. Out of the total population, the majority of the respondents were males with a total of 
$189(54 \%)$ while females were $161(46 \%)$. Most of these respondents were students with age group of 20-24 years followed by 25-29 years, below 20 years and the least age group were those above 30 years which constituted 165 (47.1\%), $141 \quad(40.3 \%), 29 \quad(8.3 \%)$ and $15 \quad(4.3 \%)$ respectively.

The second or level 200 students recorded the highest number of $130(37.1 \%)$ followed by the third years or level 300 with $110(31.4 \%)$ and the level 100 students, also $75(21.4 \%)$. The level 400 students were those who had the interest to do the national service with that particular industry. The unmarried were $289(82.6 \%)$ while married were $50(14.3 \%)$. Of the entire students, $11(3.1 \%)$ responded that they are staying with their partners but not married.

Christianity recorded the highest number among the religion category with $235(67.1 \%)$ while Muslims recorded $105(30 \%)$.Two hundred and forty six (246) representing $70.3 \%$ were those who used the commercial vehicle as means of transport to work, $62(17.7 \%)$ of them used their private or joined a family member vehicle to work while $42(12 \%)$ of them used other means such as by walking, joined the company or industry vehicle, motor and bicycle.

With regards to academic institution of respondents, it came to the light that, $172(49.1 \%)$ of them were from both private and public universities, $168(48 \%)$ also from the ten polytechnics in the country while $10(2.9 \%)$ from other institutions such as Institute of Business Management and Journalist (IBM\&J) and Intercom Programming and Manufacturing Company( IPMC) Limited Ghana.

More so, students reading Business related courses were the majority followed by Science, Social Sciences, Arts and Engineering with the total of $118(33.7 \%), 82(23.4 \%)$, $75(21.4 \%), 39(11.1 \%)$ and $36(10.3 \%)$ respectively. However, the majority of the respondents had the chance at the public sector of the economy with a total of $180(51.4 \%)$, $127(36.3 \%)$ at the private sector of the economy and $43(12.3 \%)$ with the Non-Governmental Organizations (NGO's) as indicated on Table 1. below.

Table 1. Background characteristics of Respondents.

\begin{tabular}{lll}
\hline Variable & Characteristics & Number (\%) \\
\hline Gender & Female & $161(46 \%)$ \\
Age Bracket & Male & $189(54 \%)$ \\
& $<20$ & $29(8.3 \%)$ \\
Level of study & $20-24$ & $165(47.1 \%)$ \\
& $25-29$ & $141(40.3 \%)$ \\
& $30<$ & $15(4.3 \%)$ \\
Marital Status & 100 & $75(21.4 \%)$ \\
& 200 & $130(37.1 \%)$ \\
Religion & 300 & $110(31.4 \%)$ \\
& 400 & $35(10 \%)$ \\
& Single & $289(82.6 \%)$ \\
Mode of transport & Married & $50(14.3 \%)$ \\
& Others & $11(3.1 \%)$ \\
& Christian & $235(67.1 \%)$ \\
& Muslim & $105(30 \%)$ \\
& Others & $10(2.9 \%)$ \\
& Private & $62(17.7 \%)$ \\
& Commercial & $246(70.3 \%)$ \\
\hline
\end{tabular}

\begin{tabular}{lll}
\hline Variable & Characteristics & Number (\%) \\
\hline Academic Institution & Polytechnic & $168(48 \%)$ \\
& University & $172(49.1 \%)$ \\
& Others & $10(2.9 \%)$ \\
Academic Discipline & Science & $82(23.4 \%)$ \\
& Arts & $39(11.1 \%)$ \\
& Engineering & $36(10.3 \%)$ \\
& Social Science & $75(21.4 \%)$ \\
& Business & $118(33.7 \%)$ \\
Sector of Economy & Public & $180(51.4 \%)$ \\
& Private & $127(36.3 \%)$ \\
& NGO's & $43(12.3 \%)$ \\
\hline
\end{tabular}

Respondents were asked to rate their satisfaction level with regards to the challenges as to whether they agreed or disagreed with the component.

Majority of the respondents (71.4\%) agreed to their place of attachment though it wasn't their main choice. However, $25.4 \%$ disagreed to the place of attachment being unsuitable to them, $3.1 \%$ were neutral. $47.7 \%$ agreed to the fact that the work scheduled were overloaded on them but on the other hand $22 \%$ disagreed while $30.3 \%$ were not specific to themselves as they had responded to be at the neutral position.

With regards to supervision, $66 \%$ of them agreed to the fact that supervisors were very supportive in areas of mentoring them whereas $28.3 \%$ disagreed to the fact that supervisors were supportive. The attachment duration were known to be not adequate as $60.6 \%$ of the respondents disagree while $16.9 \%$ agreed to duration adequate. $22.6 \%$ were at neutral position as the duration will be increased or decreased is none of their business.

Job description was considered too as $63.7 \%$ agreed that jobs were spelt out while $9.7 \%$ still disagreed. Additionally, $55.1 \%$ disagree that their places of attachment were not familiar while $27.4 \%$ were of different view.

Furthermore, $81.1 \%$ of the respondents disagreed that they were allocated conducive office space during the attachment. That is, most of the offices are not conducive due to small sizes of the room and inadequate logistics found while $14.3 \%$ also agreed that they were given conducive offices. Again, $74.1 \%$ also disagreed that the work environment were friendly while $25.4 \%$ on other hand agreed (Table 2).

Table 2. Respondents Measurement Levels on Challenges.

\begin{tabular}{llll}
\hline Challenge & & $\begin{array}{l}\text { Measurement Level } \\
(\%)\end{array}$ \\
\hline & Disagree & Neutral & Agree \\
\hline Place of attachment(Suitable) & 25.4 & 3.1 & 71.4 \\
Work schedule(Overloaded) & 22 & 30.3 & 47.7 \\
Supervisor(Supportive) & 66 & 5.7 & 28.3 \\
Attachment duration(Adequate) & 60.6 & 22.6 & 16.9 \\
Job description(Well Spelt Out) & 9.7 & 26.6 & 63.7 \\
Activity assigned At Work & 55.1 & 17.4 & 27.4 \\
Place(Familiar) & 81.1 & 4.6 & 14.3 \\
Office space(Conducive) & 71.4 & 3.1 & 25.4 \\
Work environment(Friendly) & & & \\
\hline
\end{tabular}

It could be observed from Table 3 that the p-value obtained is less than 0.05 , meaning the full model fits 
significantly better than the empty model (intercept only model).

This really suggests that inclusion of the study variablessatisfaction level contributes significantly to the model.

Table 3. Model Fit Statistics.

\begin{tabular}{lllll}
\hline Model & $\mathbf{- 2}$ Log Likelihood & Chi-Square & df & Sig. \\
\hline Intercept Only & 207.409 & & & \\
Full model & 159.276 & 48.132 & 21 & 0.001 \\
\hline
\end{tabular}

Table 4. Pseudo R Square of the Logit Regression Model for SIAP

\begin{tabular}{ll}
\hline Statistic & Proportion of total Variance \\
\hline Cox and Snell R square & 0.349 \\
Nagelkerke R square & 0.414 \\
McFadden R square & 0.232 \\
\hline
\end{tabular}

From Table 4, it could be observed that the Cox and Snell pseudo R square is 0.349 . Moreover, Nagelkerke pseudo R square and McFadden $\mathrm{R}$ square pseudo are 0.414 and 0.232 respectively. These imply the model explains a moderate proportion of the total variability in our data. In conclusion, these findings depict that the fitted model is consistent with the data used in this research.

Results of the ordinal logistic model fitted to the SIAP data are presented in Table 5. The coefficient estimates, $95 \%$ confidence interval and p-values for all the explanatory variables are shown. From the model the estimated threshold for very dissatisfied perception about industrial attachment is -4.186 while that of dissatisfied is 2.813. Again, for satisfied perception about SIAP the estimated threshold is 1.707 .

Table 5. Ordered Logistic Regression of the association between SIAP and Socio-demographic Characteristics.

\begin{tabular}{|c|c|c|c|c|}
\hline \multirow[t]{2}{*}{ Variable } & \multirow[t]{2}{*}{ Estimate } & \multicolumn{2}{|c|}{ 95\% Confidence Interval } & \multirow{2}{*}{$\begin{array}{l}\text { P-Value } \\
\text { und }\end{array}$} \\
\hline & & Lower Bound & Upper & \\
\hline \multicolumn{5}{|l|}{ Threshold } \\
\hline Very Dissatisfied & -4.186 & -9.14 & 0.767 & 0.098 \\
\hline Dissatisfied & -2.813 & -7.675 & 2.049 & 0.257 \\
\hline Satisfied & 1.707 & -3.123 & 6.537 & 0.488 \\
\hline Gender & -1.174 & -2.29 & -0.058 & 0.039 \\
\hline Age & 0.026 & -0.782 & 0.834 & 0.95 \\
\hline Level Of Student & -0.304 & -0.913 & 0.305 & 0.328 \\
\hline Marital Status & -1.995 & -3.123 & -0.867 & 0.001 \\
\hline Religion & 0.668 & -0.352 & 1.688 & 0.199 \\
\hline Mode Transport & 0.253 & -0.208 & 0.713 & 0.282 \\
\hline $\begin{array}{l}\text { Academic } \\
\text { Institution }\end{array}$ & 0.099 & -0.819 & 1.018 & 0.832 \\
\hline $\begin{array}{l}\text { Academic } \\
\text { Discipline }\end{array}$ & -0.008 & -0.324 & 0.307 & 0.959 \\
\hline $\begin{array}{l}\text { Sector Of } \\
\text { Economy }\end{array}$ & 0.425 & -0.332 & 1.182 & 0.272 \\
\hline $\begin{array}{l}\text { Department } \\
\text { Attached }\end{array}$ & 0.298 & -0.121 & 0.718 & 0.163 \\
\hline $\begin{array}{l}\text { Number Of } \\
\text { Supervisors }\end{array}$ & -0.304 & -0.84 & 0.232 & 0.266 \\
\hline Working Hours & -0.582 & -1.469 & 0.304 & 0.198 \\
\hline $\begin{array}{l}\text { Place Of } \\
\text { Attachment }\end{array}$ & 0.502 & 0.052 & 0.952 & 0.029 \\
\hline
\end{tabular}

\begin{tabular}{lllll}
\hline Variable & Estimate & \multicolumn{2}{l}{ 95\% Confidence Interval } & \multicolumn{2}{c}{ P-Value } \\
\hline & & Lower Bound & \multicolumn{2}{c}{ Upper Bound } \\
\hline Work Schedule & 0.339 & -0.08 & 0.757 & 0.113 \\
Supervisor & 0.936 & 0.21 & 1.662 & 0.012 \\
Attachment & -0.168 & -0.684 & 0.349 & 0.525 \\
Duration & -0.277 & -0.862 & 0.308 & 0.354 \\
Job Description & -0.861 & -1.393 & -0.329 & 0.002 \\
Activity Assigned & 0.631 & 0.059 & 1.202 & 0.031 \\
Office Space & -0.238 & 0.989 & 0.23 \\
Work & 0.376 & & & \\
Environment & & &
\end{tabular}

Hypothesis

$H_{0}$ : Slope coefficients are the same across response categories.

$H_{1}$ : Slope coefficients are not the same across response categories.

Following the results of the ordinal logistic model, it is evident that gender ( $p$-value=), marital status, place of attachment, supervisor, activity assigned at work place and working space comfortability are the main factors that influence students' perception about industrial attachment. Whilst gender and marital status negatively relate to students' perception about industrial attachment for place of industrial attachment, supervisor and office space positive associations with students' perception were found. Positive association regarding office, supervisor, place of industrial attachment means such variables increases students perception rating from low to high while negative associations refers decrease in students perception in SIAP rating from low to high. Using the logit coefficients of the significant variables, the respective ordinal logistic models for very dissatisfied, dissatisfied and satisfied perception about SIAP are given by

$$
\begin{gathered}
\text { Logit(Very dissatisfied) }= \\
-4.186-1.174 * \mathrm{GD}-1.995 * \mathrm{MS}+0.502 * \mathrm{PIA} \\
+0.936 * \mathrm{SP}+0.631 * \mathrm{OS} \\
\text { Logit(Dissatisfied) }=-2.183-1.174 * \mathrm{GD}-1.995 * \\
\text { MS }+0.502 * \mathrm{PIA}+0.936 * \mathrm{SP}+0.631 * \mathrm{OS} \\
\text { Logit(Satisfied) }=1.707-1.174 * \mathrm{GD}-1.995 * \mathrm{MS}+ \\
0.502 * \mathrm{PIA}+0.936 * \mathrm{SP}+0.631 * \mathrm{OS}
\end{gathered}
$$

Where GD is gender, MS is marital status, PIA is place of industrial attachment, SP is supervisor and OS is office space. To classify the significant factors under the categories perceived status of SIAP, the latent variable model below was developed.

$$
y=\left\{\begin{array}{cc}
\text { very dissatisfied } & \text { if } y^{*} \leq-4.186 \\
\text { dissatisfied } & -4.186<y^{*} \leq-2.183 \\
\text { satisfied } & -4.186<y^{*} \leq 1.707 \\
\text { very satisfied } & 1.707<y^{*} \leq \infty
\end{array}\right.
$$

However, the remaining factors including age, religion, and mode of transport, level of students, academic institution, academic discipline, sector of economy among others appeared to be statistically insignificant at 5\% level.

From Equation 1 an estimate for the category of SIAP 
associated with the female gender controlling the effect of other variables is found by

$$
\begin{gathered}
\text { Logit (Very dissatisfied })=-4.186-1.174(1)- \\
1.995(0)+0.502(0)+0.936(0)+0.63(0) \\
=-4.186-1.174(1)=-5.36
\end{gathered}
$$

With this, the latent variable model obtaining a value of 5.36 falls within the range of very dissatisfied. This suggests that the logit of students being dissatisfied about industrial attachment is associated with female gender. Moreover, controlling the effect of other variables, the estimate of perception towards SIAP for the male gender is

$$
\begin{gathered}
\text { Logit }(\text { Very dissatisfied })=-4.186-1.174(2)- \\
1.995(0)+0.502(0)+0.936(0)+0.63(0) \\
=-4.186-1.174(2)=-6.534
\end{gathered}
$$

Similarly, the logit of -6.534 indicating the logit of students being dissatisfied with industrial attachment is associated with male gender. In controlling the effect of other variables, the estimate of perception towards SIAP for students with single marital status is

$$
\begin{gathered}
\text { Logit }(\text { Very dissatisfied })=-4.186-1.174(0)- \\
1.995(1)+0.502(0)+0.936(0)+0.63(0) \\
=-4.186-1.995(1)=-6.181
\end{gathered}
$$

Similarly, the logit of -6.181 indicating the logit of students being dissatisfied about industrial attachment is associated with single marital status. Correspondingly, the logit of students being dissatisfied about industrial attachment is associated with students who were married:

$$
\begin{gathered}
\text { Logit }(\text { Very dissatisfied })=-4.186-1.174(0)- \\
1.995(2)+0.502(0)+0.936(0)+0.63(0) \\
=-4.186-1.995(2)=-8.176
\end{gathered}
$$

Table 6. Test of parallel lines for the Proportional Odds model.

\begin{tabular}{lllll}
\hline Model & $\begin{array}{l}\mathbf{- 2} \text { Log } \\
\text { Likelihood }\end{array}$ & Chi-Square & df & p-value \\
\hline $\begin{array}{l}\text { Constrained } \\
\text { model }\end{array}$ & 159.276 & & & \\
$\begin{array}{l}\text { General model } \\
99.886^{\mathrm{b}}\end{array}$ & $59.390^{\mathrm{c}}$ & 42 & 0.080 \\
\hline
\end{tabular}

As indicated on table 6, the chi-square value of 59.390 resulting from the difference between the log likelihood of the constrained model and general model is relatively large. This value corresponds to a p-value of 0.080 which is larger than $5 \%$ level of statistical significance. This implies that the test is not significant at 5\% level. Therefore there is no evidence to reject the null hypothesis. Hence, the coefficients are the same across the three categories of rate of satisfaction level of the SIAP and that the fitted logit of the proportional odds models are parallel. These depict that the proportional odds model developed in this paper is valid and consistent with the SIAP data.

\section{Conclusion}

The very perceptions about SIAP in Ghana seem not over. Evidences from our result so far do not only support this assertion but rather complement challenges facing the Programme up to date. Gender, marital status, place of attachment, supervisor, and activity assigned at work place and working space (conducive) were the main factors that influenced students' perception about industrial attachment. While gender and marital status showed negative association on students' perception about industrial attachment, place of industrial attachment, supervisor and office space showed positive associations. The paper highlights the weakness and strengths in SIAP in Ghana. We therefore emphasize that the authorities in charge of industrial attachment pay attention to the findings of the study; so that with this, we might be able to improve the environment of industrial attachment to suit the interest of students. Also, this study would assist tertiary institutions particularly those in the metropolis in making necessary amendments in the management of their existing SIAP.

\section{References}

[1] Afonja, A.A., Sraku-Lartey, K and Oni, S.A (2005) Engineering Education for Industrial Development: Case Studies of Nigeria, Ghana and Zimbabwe. Nairobi: ATPS Working Paper. No. 42. The African Technology Policy.

[2] Agresti, A. (2002). Categorical Data Analysis. WileyInterscience. A John Wiley \& Sons Inc., publications, second edition.

[3] Carlson, A.C (2002) 'The Benefits of Work-integrated Learning', ITE Teachers' Conference, Malaysia.

[4] Dickinson, B (2010) 'Riffs and Jams, Beside and Seaside.' The Training Journal. 10(1): 1-17.

[5] Finch, C, R. \& Crunkilton, J, R (1999). Curriculum Development in Vocational and Technical Education: Planning, Content and Implementation, 5th Edition, Boston: Allyn and Bacon.

[6] Gumbe, S.M, Svotwa, T.D \& Mupambireyi, F.P (2012) "Students' Perspectives of the Industrial Attachment Programme: A Study of University of Zimbabwe Faculty of Commerce Students (2010-2011)" International Journal of Physical and Social Sciences, 2, (9): 12-36.

[7] Olugbenga, A, F (2009) 'Towards Effective SIWES Curriculum Development in Applied Sciences for Adequate Skills Utilization: A Case Study of the School of Applied Science, Nuhu Bamali Polytechnic, Zaria' Pacific Journal of Science and Technology, 10(1): 234-239.

[8] Oguntimehin, a (2001). Teacher Effectiveness: Some Practical Strategies for Successful Implementation of Universal Basic Education in Nigeria. African Journal of Educational Management, 9(1): 151-161.

[9] Petter, J (2009). Learning to be a Person in Society, London: Rout ledge. 
[10] Peterson, R. A (2000). Constructing Effective Questionnaires. London: Sage Publications.

[11] Rae, L (1998). Using People Skills in Training and Development, London: Kogan Page.
[12] Samuel, F (2005). SIWES Orientation Programme of the Federal University of Technology. Paper presented by the Industrial Training Fund. Minna, Nigeria, July. 